\title{
Oat fibers modification by reactive extrusion with alkaline hydrogen peroxide
}

\author{
Melina Aparecida Plastina Cardoso ${ }^{1}$, Gizilene Maria Carvalho², Fabio Yamashita1, Suzana Mali ${ }^{3}$ \\ Juliana Bonametti Olivato ${ }^{1}$ and Maria Victoria Eiras Grossmann ${ }^{1 *}$
}

\author{
${ }^{1}$ Departamento de Ciência e Tecnologia de Alimentos, Universidade Estadual de Londrina - UEL, \\ Londrina, PR, Brazil \\ ${ }^{2}$ Departamento de Química, Universidade Estadual de Londrina - UEL, Londrina, PR, Brazil \\ ${ }^{3}$ Departamento de Bioquímica, Universidade Estadual de Londrina - UEL, Londrina, PR, Brazil \\ *victoria@uel.br
}

\begin{abstract}
The modification of lignocellulosic fibers can enhance their interaction with other materials and alkaline hydrogen peroxide (AHP) is a reagent widely used to promote such modification. This work aimed to modify oat hulls fibers by

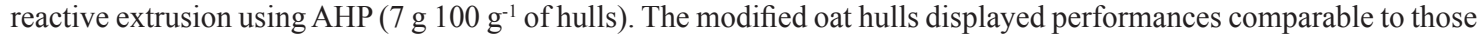
observed by other researchers using conventional AHP method (without extrusion). The AHP treated oat hulls showed increased luminosity compared to the extruded ones. Fourier transform infrared spectroscopy showed differences between the modified and unmodified structures. The removal of surface compounds resulted in a more open morphology, with greater surface area and greater porosity. Reactive extrusion can be an alternative method for fiber modification with several advantages, such as short processing time and no wastewater generation.
\end{abstract}

Keywords: chemical modification, lignocellulosic fibers, microstructure, thermal stability.

\section{Introduction}

In the last decades, discarded plastic materials are accumulated in the environment, as a consequence of the resistance of polymers derived from petroleum to natural degradation. The substitution by natural or synthetic biodegradable polymers has been extensively studied because they degrade more rapidly compared to traditional polymers. However, the majority of biodegradable polymers (polyhydroxyalkanoates (PHAs), polyhydroxybutyrate (PHB), polylactic acid (PLA), polycaprolactones (PCL)) are higher in cost and possess inferior mechanical properties compared with, for example, high-density polyethylene (HDPE) and low-density polyethylene (LDPE) $)^{[1,2]}$. Starch, a natural, low-cost polymer from renewable sources, also produces materials with diminished mechanical properties and high moisture sensitivity, even when used in blends with other biodegradable polymers ${ }^{[3-7]}$. In this context, natural fibers have been studied as a good alternative for reinforcement being mixed with pure biodegradable polymers or their blends to form composites with reduced environmental impact ${ }^{[8]}$. Fibers of curaua, jute, sisal, sugarcane, and others have been tested for this purpose $\mathrm{e}^{[4,8-15]}$.

Oat hulls (a byproduct from the processing of oat grains, rich in fiber) are an interesting option for use as reinforcement in composites. Studies have been conducted with the inclusion of these fibers in trays of cassava starch (produced by extrusion followed by thermoforming) with good results ${ }^{[16]}$.

However, despite their several advantages, such as low cost, easy accessibility and high biodegradability, cellulosic fibers present problems in terms of fiber - matrix adhesion and changes in water absorption, and the mechanical properties of some composites can remain unsatisfactory ${ }^{[17]}$. Aiming to overcome these limitations, the modification of fibers has been proposed ${ }^{[18]}$.

To improve the compatibility of natural fibers with polymers, several authors ${ }^{[17,19-25]}$ proposed the surface modification of fibers from different sources. These modifications decrease fiber hydrophilicity and/or increase adhesion with the polymer matrix, enhancing the thermal and mechanical properties of the composites. Various reagents are used, including sodium hydroxide $(\mathrm{NaOH}) ; \mathrm{NaOH}$ in combination with other reagents, such as hydrogen peroxide $\left(\mathrm{H}_{2} \mathrm{O}_{2}\right)$; and hot water with the subsequent addition of neutral detergents.

When alkaline hydrogen peroxide (AHP) is applied to the fiber, the components responsible for its natural color become oxidized (bleaching action) and the hydrolysis of the lignin macromolecule may occurs. The intensity of hydrolysis, as well as the modification degree, are dependent on the reaction conditions ${ }^{[19,26]}$. Other reactions include the conversion of lignin phenolic groups in aldehyde, carbonyls and quinones and, in the most dramatic cases, the disruption of aromatic rings ${ }^{[27]}$.

The modification of the fibers is typically achieved by employing conventional reactors, which require long reaction times (up to $48 \mathrm{~h}$ ) and generate large volumes of effluent ${ }^{[28]}$. The advantages of using reactive extrusion are a drastic reduction in the reaction time and the lack of effluents. Although corrosion-resistant materials (more expensive) would have to be used in the manufacture of the screw and barrel to protect against possible corrosion caused by the use of chemicals, the process would be recommended. Additionally, reagents not consumed in the 
reaction and/or degradation products will be present in the modified fiber and may affect, positively or negatively, its future applications.

In a preliminary study, aiming the application in food products, our research group employed reactive extrusion with AHP to modify the fibers of oat hulls ${ }^{[29]}$. The characterization was limited to the hydration properties of the fibers. Now, looking the possible use of these fibers as reinforcing agents in biodegradable polymeric matrices, this work was carried out in order to promote its modification by a similar process, characterizing the modified fibers in relation to their physical, thermal and microstructural properties.

\section{Materials and Methods}

\subsection{Materials}

The fiber source was micronized oat hulls $\left(4.64 \mathrm{~g} 100 \mathrm{~g}^{-1}\right.$

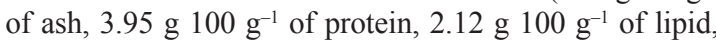

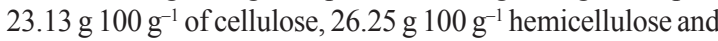

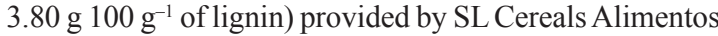
Ltda (Mauá da Serra, Brazil). Hydrogen peroxide $200 \mathrm{~V}$, (Biotec, Pinhais, Brazil) and $\mathrm{NaOH}$ (Synth, Diadema, Brazil) were also used.

\subsection{Oat fiber modification}

The micronized hulls ( $250 \mathrm{~g})$ were modified by reactive extrusion with alkaline hydrogen peroxide according Galdeano and Grossmann ${ }^{[29]}$. Initially, the hulls were conditioned to $32 \%$ moisture by adding the required volume of water containing dissolved enough $\mathrm{NaOH}$ for the material to reach a $\mathrm{pH}$ of 11.5. The conditioned hulls were placed in a sealed polyethylene bag and allowed to equilibrate under refrigeration (7-10 ${ }^{\circ} \mathrm{C}$ ) for 24 hours, for moisture balance. Next, the hulls were removed from the refrigerator and allowed to rest for 1 hour to attain the ambient temperature and $34 \mathrm{~mL}$ of hydrogen

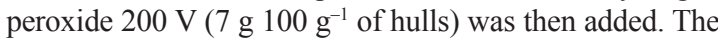
material was extruded in a single screw extruder (AX Plasticos, Diadema, Brazil) with $\mathrm{D}=1.6 \mathrm{~cm}, \mathrm{~L} / \mathrm{D}=40$, four heating zones and a $0.8 \mathrm{~mm}$ die diameter. The processing temperatures in all zones were maintained at $110^{\circ} \mathrm{C}$, and the screw speed was $100 \mathrm{rpm}$ with constant feeding. These conditions were established from preliminary tests. The steady state was controlled by maintaining constant amperage. After extrusion, the samples were dried $\left(60^{\circ} \mathrm{C} / 24 \mathrm{~h}\right)$ and coarsely ground in a blender (Arno, São Paulo, Brazil) followed by a second ground in a table mill (IKA A-11 Basic Mill - São Paulo - Brazil). To assess the effect of the extrusion process, a sample was processed by the same procedure but without the addition of reagents (sodium hydroxide and hydrogen peroxide). All obtained materials were divided into two equal portions, one of which underwent washing with 10 volumes of distilled water and was then stored in a refrigerator for 6 hours for decantation. Subsequently, the supernatant was discarded, and the remaining material was dried in an oven at $60{ }^{\circ} \mathrm{C}$ for $24 \mathrm{~h}$. This wash was performed to assess the removal of compounds that were solubilized by processing without using large amounts of water, as used in traditional processes. Thus, five different samples were obtained: F1untreated fiber, F2- fiber modified by extrusion, F3- fiber modified by extrusion and then washed, F4- fiber modified by AHP and F5- fiber modified by AHP and then washed. All assays were performed in duplicate.

\subsection{Physical properties of the fibers}

The luminosity $\left(\mathrm{L}^{*}\right)$ of the samples was measured with a Minolta CR-10 portable colorimeter (Sino Devices, Georgia, United States) using CIE illuminant D65 (natural daylight) placed at an angle of $8 / \mathrm{d}$ and a 10th CIE standard observer with an $8 \mathrm{~mm}$ diameter reading area. The fiber samples were placed in a plastic container $(1 \mathrm{~cm}$ in height and $4 \mathrm{~cm}$ in diameter). The water absorption index (WAI) and the swollen volume (SV) were determined using the methods described by Seibel and Beleia ${ }^{[30]}$. The WAI was obtained by the ratio between the weight of the wet sample and the initial dry weight and the volume of the wet sample was considered SV. The analysis were performed in triplicate.

\subsection{Scanning electron microscopy}

The fibers were analyzed for their microstructure by scanning electron microscopy (SEM) using an electron microscope (FEI Quanta 200, North Carolina, United States). Before the analysis, the samples were pre-dried at $60^{\circ} \mathrm{C}$ for 24 hours and left in a desiccator with silica for 24 hours. The dried samples were then coated with a 15 to $20 \mathrm{~nm}$ layer of gold using a Sputter Coater BAL-TEC SCD 050 (Baltec, Balzers, Liechtenstein) prior to analysis.

\subsection{Fourier transform infrared (FTIR) spectroscopy}

Only for this analysis, the samples were washed with large amount of distilled water, aiming to facilitate the detection of modifications promoted by the treatments. Therefore, only the samples F1, F2 and F4 were analysed. After washing, the samples were dried in an oven at $60{ }^{\circ} \mathrm{C}$ for 24 hours and maintained in a desiccator with silica for 24 hours. The FTIR spectra were obtained with a spectrophotometer (FT-IR/NIR Spectrmeter Spectrum Frontier, São Paulo, Brazil). The analyses were performed in the mid-infrared, covering wave numbers from 4000 to $400 \mathrm{~cm}^{-1}$, with $2 \mathrm{~cm}^{-1}$ resolution. A total of 32 scans were performed on each sample.

\subsection{Thermogravimetric analysis (TGA)}

Samples of approximately $13.5 \mathrm{mg}$ were used and subjected to the following analysis conditions: temperature range of $30{ }^{\circ} \mathrm{C}-800{ }^{\circ} \mathrm{C}$, heating rate of $20{ }^{\circ} \mathrm{C} / \mathrm{min}$ and nitrogen atmosphere. The equipment used was a TGA 4000 (Waltham, Massachusetts, USA).

\subsection{Statistical analysis}

Statistical evaluation was performed by analysis of variance (ANOVA). Means were compared by the Tukey test at a 5\% significance level.

\section{Results and Discussions}

It is important to note that, while other studies characterized modified fibers that had been thoroughly washed, in the present work the samples were unwashed or were washed with only 10 volumes of water, aiming to take advantage of no waste production. 


\subsection{Physical properties of fiber hulls}

The physical measurements of color (luminosity), water absorption indices (WAI) and swelling volumes (SV) of the oat hull samples are shown in Table 1. Regarding the luminosity, it was observed that the treatment of the husks (fiber) only by extrusion (F2) caused darkening (decreased L*), which could be related to the high temperature used in the process, which would induce caramelization and Maillard reactions $^{[31]}$.

When these extruded fibers were washed (F3), no whitening effect was observed, indicating that the formed compounds responsible for the darkening were insoluble. Furthermore, when the fibers were treated with AHP (F4), discoloration was noticed (increase in brightness) compared with F2 and F3, due to the oxidation of the pigments that impart dark color to the natural fibers. Thus, the darkening effect of extrusion was compensate by the bleaching effect of AHP treatment. After chemical treatment and subsequent washing (F5), the fibers showed an even greater increase in brightness, indicating that, in addition to the oxidation of the pigments, the hydrolysis of the pigments and/or of lignin also occurred forming soluble compounds that were removed in the wash. Similar effects were observed by other researchers ${ }^{[28,32]}$.

It is well stablished the water absorption process of the lignocellulosic fibers shows two phases, requiring long times for the fully hydration. However, the first phase (corresponding to the Fick law diffusion) has a high absorption coefficient and is completed in $10-15 \mathrm{~min}$. The water intake in this phase results from a capillary action (due to the porous structure) and this will be the phase directly impacted by any modification in the fiber promoted by the treatments. Thus, the WAI was determined by a methodology widely used by several researchers, in which the immersion time of fiber in water is $30 \mathrm{~min}$ aiming to identify the occurrence of modification, even though the fiber was not fully hydrated.
Only the oat fiber modified by AHP (F4) behaved differently from the untreated fiber (F1) in terms of water absorption (Table 1), indicating this treatment modified the fibers structure. A comparison of the smallest value (observed in the untreated fiber) with the highest value (observed in the fiber treated with peroxide) showed that the water uptake increased $36.12 \%$ after treatment. This can be attributed to the increased exposure of hydroxyls in the cellulose after the hydrolysis of some of the lignin fractions by chemical treatment with AHP. Gould, Jasberg and Cote ${ }^{[33]}$ also observed increased water uptake in wheat straw treated with AHP. The effect of the possible removal of hemicelluloses ${ }^{[34]}$ from the fiber structure should also be considered. Their removal exposes macromolecules of cellulose, causing large voids that would facilitate the water entry ${ }^{[35]}$. Thus, the increase of WAI in F4 must also have resulted from the retention of water in the interstitial spaces of the cell wall, which were more accessible after chemical treatment.

The same factors that increased the WAI could have contributed to the higher swelling of the fibers, but this was not observed (Table 1). Statistically, there were no differences in the swollen volume values. This could be due to the saturation of the cell wall of the fiber with water, which would decrease the flexibility of the wet fiber and limit the differences among the samples ${ }^{[36]}$. The observed result is interesting for the application of the modified fibers in composites, in which changes in the volume of fibers motivated by water intake are undesirable.

\subsection{Morphologic characterization (SEM)}

The images of untreated (F1) extruded (F2) and treated by AHP (F4) fibers are shown in Figure 1. The partially washed samples (F3 and F5) are not displayed because their similarity with the corresponding unwashed (F2 and F4, respectively). Analyzing the morphology of the untreated fiber (F1), beams oriented in the longitudinal direction that

Table 1. Luminosity, water absorption index and swollen volume of oat hulls under different treatments.

\begin{tabular}{cccc}
\hline Samples & $\begin{array}{c}\text { Luminosity* } \\
\text { (L) }\end{array}$ & $\begin{array}{c}\text { WAI* } \\
\left.\text { (g wet fibers g dry fiber }^{-1}\right)\end{array}$ \\
\hline F1 & $44.83 \pm 0.07^{\mathrm{b}}$ & $2.99 \pm 0.08^{\mathrm{a}}$ & $3.0 \pm 0.2^{\mathrm{a}}$ \\
F2 & $34.41 \pm 0.37^{\mathrm{a}}$ & $3.53 \pm 0.14^{\mathrm{ab}}$ & $3.1 \pm 0.5^{\mathrm{a}}$ \\
F3 & $35.27 \pm 0.21^{\mathrm{a}}$ & $3.72 \pm 0.31^{\mathrm{ab}}$ & $3.3 \pm 0.5^{\mathrm{a}}$ \\
F4 & $45.76 \pm 0.21^{\mathrm{b}}$ & $4.07 \pm 0.16^{\mathrm{b}}$ & $3.4 \pm 0.4^{\mathrm{a}}$ \\
F5 & $51.43 \pm 0.17^{\mathrm{c}}$ & $3.44 \pm 0.30^{\mathrm{ab}}$ & $3.5 \pm 0.3^{\mathrm{a}}$ \\
\hline
\end{tabular}

*Means $(\mathrm{n}=3) \pm$ standard deviation; WAI: water absorption index; SV: swollen volume. F1: untreated fiber; F2: fiber modified by extrusion; F3: fiber modified by extrusion and washed; F4: fiber modified by AHP; F5: fiber modified by AHP and washed. Different lowercase letters in the same column indicate significant differences between the means $(\mathrm{p} \leq 0.05)$
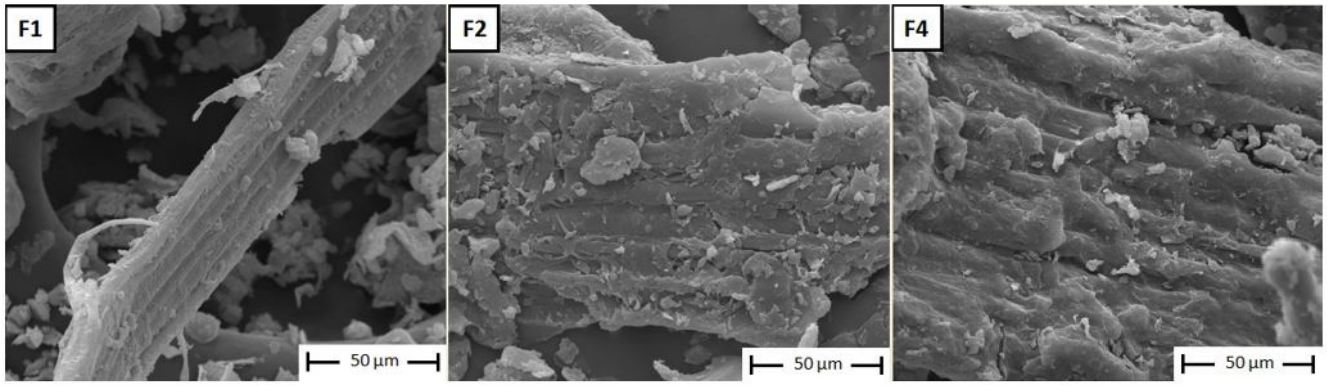

Figure 1. SEM of the fibers: untreated (F1); physically modified by extrusion (F2) and chemically modified with AHP (F4). 
were covered with a layer of material forming a smooth surface are observed, which might be a consequence of the presence of wax and other non-cellulosic materials (hemicelluloses, lignin and pectin), forming a compact structure. This surface layer is damaged in several regions, perhaps due to the milling of the oat hulls by the physically intensive micronization process.

In F2, a more rugged surface was observed compared with F1. Due to the shear forces and high temperature and pressure during extrusion coupled with the additional grinding process, more cracks were opened, making the structure more porous. An increased damage of the structure was observed in the fibers modified with AHP (F4), which displayed an increase in the number of fiber bundles and deep valleys compared with the untreated fibers (F1). Thus, it can be observed that the chemical modification increases the exposure of the surface, increasing the area of holes and valleys present throughout the rough fiber surface. This effect can be ascribed to the action of AHP coupled with the physical action of the extrusion process. Campos et al. ${ }^{[17]}$, Brígida et al. ${ }^{[19]}$, and Teodoro et al. ${ }^{[37]}$ also reported the efficient removal of waste wax and fatty acids from the surfaces of fibers after treatment with hydrogen peroxide in sisal and coconut fibers.

The modifications promoted in the fiber morphology by AHP treatment can explain the higher WAI of the treated sample (Table 1).

\subsection{FTIR}

The FT-IR spectra of samples are presented in Figure 2. The bands between $1739 \mathrm{~cm}^{-1}$ and $1022 \mathrm{~cm}^{-1}$ are enlarged (right figure) for better visualization of the region of interest concerning the changes occurring in the fibers.

The characteristic bands of the fibers correspond to the absorption bands of lignin, hemicellulose and cellulose. The absorption bands observed in these components are: $-\mathrm{OH}\left(3500-3200 \mathrm{~cm}^{-1}\right), \mathrm{C}=\mathrm{O}\left(\sim 1739 \mathrm{~cm}^{-1}\right) \mathrm{C}-\mathrm{O}-\mathrm{C}$ $\left(\sim 1259 \mathrm{~cm}^{-1}-1155 \mathrm{~cm}^{-1}\right)$ and C-OH $\left(\sim 1084 \mathrm{~cm}^{-1}-1022 \mathrm{~cm}^{-1}\right)^{[38]}$. The band at $3455 \mathrm{~cm}^{-1}$ is attributed to $\mathrm{OH}$ stretching vibrations related to the ring $(\mathrm{CH}-\mathrm{OH})$ and side chain $\left(-\mathrm{CH}_{2}-\mathrm{OH}\right)$ of cellulose. At $2920 \mathrm{~cm}^{-1}$ are the trademark stretching vibrations of $\mathrm{CH}_{2}$.

At $1739 \mathrm{~cm}^{-1}$, it is possible to observe a shoulder in the sample from the untreated fiber (F1), which can be assigned to the $\mathrm{C}=\mathrm{O}$ group of hemicellulose and/or the ester bonds of the carboxyl groups present in hemicellulose and lignin. An increase in this shoulder was observed after reaction with $\mathrm{AHP}(\mathrm{F} 4)$ when compared to the untreated fiber $(\mathrm{F} 1)$, which could indicate slight changes in hemicellulose and lignin due to AHP. According to Liu et al. ${ }^{[39]}$, the carbonyl number $(\mathrm{C}=\mathrm{O})$ initially present in the fiber can be increased by oxidation reactions or decreased by cyclization reactions, both of which are promoted by hydrogen peroxide.

The bands at $1640 \mathrm{~cm}^{-1}$ to $1424 \mathrm{~cm}^{-1}$ originate from carboxyl-conjugated carbonyl stretches, and these are generally increased after significant oxidation by hydrogen peroxide ${ }^{[40]}$. These bands are similar for samples F2 and F4, indicating that extrusion, similar to AHP, promoted changes in these chemical groups. The bands at $1380 \mathrm{~cm}^{-1}$ represent the symmetric and asymmetric deformation of the $\mathrm{C}-\mathrm{H}$ bond of cellulose and hemicellulose, which are most representative in the modified fibers (F2 and F4) relative to the untreated fiber (F1), highlighting the loss of lignin and indicating greater exposure of cellulose ${ }^{[19,40]}$. The bands at $1249 \mathrm{~cm}^{-1}$ and $1155 \mathrm{~cm}^{-1}$ represent the relative axial vibration of $\mathrm{C}-\mathrm{O}$ groups. An increase in this band was observed in the F4 sample, which could be due to an increase in carboxylic acids and a decrease in the content of phenolic hydroxyl groups as a result of changes caused by AHP on lignin ${ }^{[40,41]}$.

\subsection{Thermogravimetric analysis (TGA)}

The thermal characterization of oat hulls that were untreated (F1), treated by extrusion (F2) and treated with alkaline hydrogen peroxide (F4) through TGA appears in Figure 3. The washed samples (F3 and F5) are not presented because there were not differences when compared with the correspondent non-washed (F2 and F4, respectively).

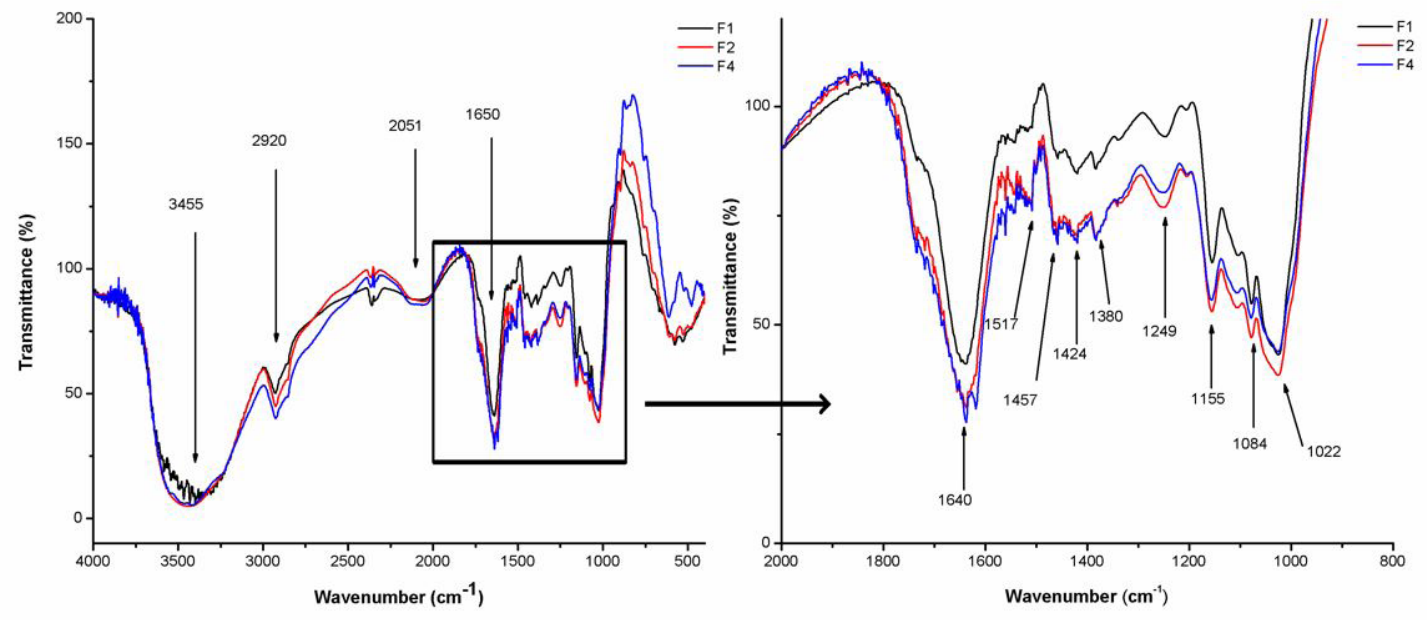

Figure 2. FTIR spectra of fibers: F1 (untreated); F2 (treated by extrusion) and F4 (treated with AHP). 

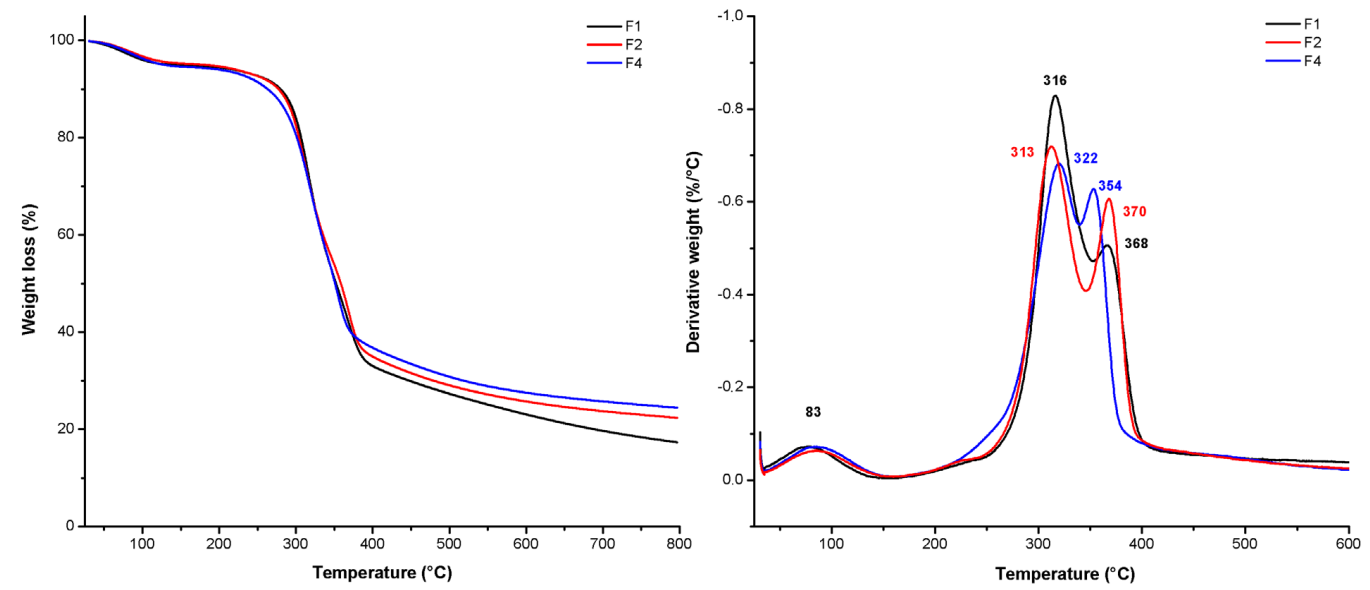

Figure 3. Thermogravimetric parameters of fibers: untreated (F1); treated by extrusion (F2) and treated with AHP (F4).

For all samples, an initial and small loss peak can be observed at the temperature of $83{ }^{\circ} \mathrm{C}$ due to the loss of water remaining in the material after the drying process. The second mass loss occurred at temperatures of $316^{\circ} \mathrm{C}$, $313{ }^{\circ} \mathrm{C}$ and $322^{\circ} \mathrm{C}$ for the $\mathrm{F} 2, \mathrm{~F} 1$ and $\mathrm{F} 4$ samples, respectively, corresponding to the degradation of hemicelluloses and pectin ${ }^{[42]}$. The weight losses at temperatures of $354^{\circ} \mathrm{C}$, $368^{\circ} \mathrm{C}$ and $370{ }^{\circ} \mathrm{C}$ (samples F4, F1 and F2, respectively) correspond to the decomposition of cellulose and lignin ${ }^{[43,44]}$.

Comparing the thermograms of the untreated oat hulls (F1) with those of the physically and chemically treated hulls (F2 and F4, respectively), it can be observed that the extrusion process did not affect the stability of the fibers, as the temperatures of the different degradation fractions were similar in samples F1 and F2. The curves of F4 showed a slight increase in the thermal stability of the hemicelluloses and pectins (peak temperature of $322{ }^{\circ} \mathrm{C}$ compared to $316{ }^{\circ} \mathrm{C}$ for the untreated hulls) and a small decrease in the temperature of degradation of cellulose and lignin (from $368^{\circ} \mathrm{C}$ in the untreated oat hulls to $354^{\circ} \mathrm{C}$ in the hulls treated with AHP). These lower differences indicated the physical and chemical treatments used were not enough to promote noticeable effects in the thermal stability of fiber components. Brígida et al. $\left[{ }^{[9]}\right.$ observed a slight increase in the thermal stability of all fractions of green coconut fiber after traditional treatment with $\mathrm{H}_{2} \mathrm{O}_{2}$.

\section{Conclusions}

Reactive extrusion can be an alternative and effective method to modify fibers and exhibits multiple advantages compared to conventional methods, including a lower processing time and the absence of effluents. These advantages can overcome the additional cost of eventually required wear resistant corrosion screw and barrel for the processing.

The extrusion process combined with hydrogen peroxide was shown to be a viable method for modifying the fiber of oat hulls, promoting bleaching, removing surface compounds and altering physical and chemical properties. FTIR revealed differences between the modified and unmodified structures, proving the efficiency of the reactive extrusion. TGA analysis showed the AHP process has no noticeable effect on the thermal stability of oat fiber. The modified fibers, which possess differentiated properties, may be considered for several applications in paper, textile and plastic industries.

\section{Acknowledgements}

The author thanks CNPQ, CAPES and UEL for the financial support given to this work.

\section{References}

1. Averous, L., \& Pollet, E. (2012). Biodegradable polymers. In L. Averous \& E. Pollet (Eds.), Environmental silicate nanobiocomposites (pp. 13-39). London: Springer.

2. Tian, H., Tang, Z., Zhuang, X., Chen, X., \& Jing, X. (2012). Biodegradable synthetic polymers: preparation, functionalization and biomedical application. Progress in Polymer Science, 37(2), 237-280. http://dx.doi.org/10.1016/j.progpolymsci.2011.06.004.

3. Garcia, P. S., Grossmann, M. V. E., Shirai, M. A., Lazaretti, M. M., Yamashita, F., Müller, C., \& Mali, S. (2013). Improving action of citric acid as compatibilizer in starch/polyester blown films. Industrial Crops and Products, 52, 305-312. http://dx.doi. org/10.1016/j.indcrop.2013.11.001.

4. Morán, J. I., Vázquez, A., \& Cyras, V. P. (2013). Bio-nanocomposites based on derivatized potato starch and cellulose, preparation and characterization. Journal of Materials Science, 48(20), 7196-7203. http://dx.doi.org/10.1007/s10853-013-7536-x.

5. Olivato, J. B., Nobrega, M. M., Müller, C. M. O., Shirai, M. A., Yamashita, F., \& Grossmann, M. V. E. (2013). Mixture design applied for the study of the tartaric acid effect on starch/ polyester films. Carbohydrate Polymers, 92(2), 1705-1710. PMid:23399209. http://dx.doi.org/10.1016/j.carbpol.2012.11.024.

6. Ren, J., Fu, H., Ren, H., \& Yuan, W. (2009). Preparation, characterization and properties of binary and ternary blends with thermoplastic starch, poly(lactic acid) and poly(butylene adipate-co-terephthalate). Carbohydrate Polymers, 77(3), 576-582. http://dx.doi.org/10.1016/j.carbpol.2009.01.024.

7. Shirai, M. A., Grossmann, M. V. E., Mali, S., Yamashita, F., Garcia, P. S., \& Müller, C. M. O. (2013). Development of biodegradable flexible films of starch and poly (lactic acid) plasticized with adipate or citrate esters. Carbohydrate Polymers, 
92(1), 19-22. PMid:23218260. http://dx.doi.org/10.1016/j. carbpol.2012.09.038.

8. Pereira, P. H. F., Freitas, M. F., Cioffi, M. O. H., Benini, K. C. C. C., Milanese, A. C., Voorwald, H. C. J., \& Mulinari, D. R. (2015). Vegetal fibers in polymeric composites: a review. Polímeros: Ciência e Tecnologia, 25(1), 9-22. http://dx.doi. org/10.1590/0104-1428.1722.

9. Lopes-Gil, A., Rodrigues-Perez, M. A., De Saja, J. A., Bellucci, F. S. \& Ardanuy, M. (2014). Strategies to improve the mechanical properties of starch-based materials: plasticization and natural fibers reinforcement. Polímeros: Ciência e Tecnologia, 24, 36-42. http://dx.doi.org/10.4322/polimeros.2014.054.

10. Karimi, S., Dufresne, A., Tahir, P. M., Karimi, A., \& Abdulkhani, A. (2014). Biodegradable starch-based composites: effect of micro and nanoreinforcements on composite properties. Journal of Materials Science, 49(13), 4513-4521. http://dx.doi. org/10.1007/s10853-014-8151-1.

11. Elbadry, E. A., Aly-Hassan, M. S., \& Hamada, H. (2012). Mechanical properties of natural jute fabric/jute mat fiber reinforced polymer matrix hybrid composites. Advances in Mechanical Engineering, 20, 1-12. http://dx.doi.org/10.1155/2012/354547.

12. Castro, D. O., Frollini, E., Marini, J., \& Ruvolo-Filho, A. (2013). Preparação e caracterização de biocompósitos baseados em fibra de curauá, biopolietileno de alta densidade (BPEAD) e polibutadieno líquido hidroxilado (PBHL). Polímeros: Ciência e Tecnologia, 23(1), 65-73. http://dx.doi.org/10.1590/S010414282013005000002.

13. Silva, R., Haraguchi, S. K., Muniz, E. C., \& Rubira, A. F. (2009). Applications of lignocellulosic fibers in polymer chemistry and in composites. Quimica Nova, 32(3), 661-671. http://dx.doi.org/10.1590/S0100-40422009000300010.

14. Mali, S., Debiagi, F., Grossmann, M. V. E., \& Yamashita, F. (2010). Starch, sugarcane bagasse fibre, and polyvinyl alcohol effects on extruded foam properties: a mixture design approach. Industrial Crops and Products, 32(3), 353-350. http://dx.doi. org/10.1016/j.indcrop.2010.05.014.

15. Corradini, E., Agnelli, J. A. M., Morais, L. C., \& Mattoso, L. H. C. (2008). Study of Properties of Biodegradable Composites of Starch/Gluten/Glycerol Reinforced with Sisal Fibers. Polímeros: Ciência e Tecnologia, 18(4), 353-358. http://dx.doi. org/10.1590/S0104-14282008000400016.

16. Debiagi, F., Mali, S., Grossmann, M. V. E., \& Yamashita, F. (2010). Effects of vegetal fibers on properties of cassava starch biodegradable composites produced by extrusion. Ciência e Agrotecnologia, 34(6), 1522-1529. http://dx.doi.org/10.1590/ S1413-70542010000600024.

17. Campos, A., Teodoro, K. B. R., Marconcini, J. M., Matosso, L. H. C., \& Martins-Franchetti, S. M. M. (2011). Effect of fiber treatments on properties of thermoplastic starch/polycaprolactone/ sisal biocomposites. Polímeros: Ciência e Tecnologia, 21(3), 217-222. http://dx.doi.org/10.1590/S0104-14282011005000039.

18. Reddy, N., \& Yang, Y. (2005). Biofibers from agricultural byproducts for industrial applications. Trends in Biotechnology, 23(1), 22-27. PMid:15629854. http://dx.doi.org/10.1016/j. tibtech.2004.11.002.

19. Brígida, A. I. S., Calado, V. M. A., Gonçalves, L. R. B., \& Coelho, M. A. S. (2010). Effect of chemical treatments on properties of green coconut fiber. Carbohydrate Polymers, 79(4), 832-838. http://dx.doi.org/10.1016/j.carbpol.2009.10.005.

20. George, J., Sreekala, M. S., \& Thomas, S. (2001). A review on interface modification and characterization of natural fiber reinforced plastic composites. Polymer Engineering and Science, 41(9), 1471-1485. http://dx.doi.org/10.1002/pen.10846.

21. Hassan, M. L., Hassan, E. A., \& Oksman, K. N. (2011). Effect of pretreatment of bagasse fibers on the properties of chitosan/ microfibrillated cellulose nanocomposites. Journal of Materials
Science, 46(6), 1732-1740. http://dx.doi.org/10.1007/s10853010-4992-4.

22. Kim, H., Okubo, K., Fujii, T., \& Takemura, K. (2013). Influence of fiber extraction and surface modification on mechanical properties of green composites with bamboo fiber. Journal of Adhesion Science and Technology, 27(12), 1348-1358. http:// dx.doi.org/10.1080/01694243.2012.697363.

23. Mwaikambo, L. Y., \& Ansell, M. P. (2001). Chemical modification of hemp, sisal, jute, and kapok fibers by alkalization. Journal of Applied Polymer Science, 84(12), 2222-2234. http://dx.doi. org/10.1002/app.10460.

24. Ray, D., Sarkar, B. K., Rana, A. K., \& Bose, N. R. (2001). Effect of alkali treated jute fibers on composite properties. Bulletin of Materials Science, 24(2), 129-135. http://dx.doi. org/10.1007/BF02710089.

25. Sinha, E., \& Rout, S. K. (2009). Influence of fiber surface treatment on structural, thermal and mechanical properties of jute fiber and its composite. Bulletin of Materials Science, 32(1), 65-76. http://dx.doi.org/10.1007/s12034-009-0010-3.

26. Correia, J. A. C., Marques, J. E., Jr., Gonçalves, L. R. B., \& Rocha, M. V. P. (2013). Alkaline hydrogen peroxide pretreatment of cashew apple bagasse for ethanol production: study of parameters. Bioresource Technology, 139, 249-256. PMid:23665519. http://dx.doi.org/10.1016/j.biortech.2013.03.153.

27. Mancera, A., Fierro, V., Pizzi, A., Dumarçay, S., Gérardin, P., Velásquez, J., Quintana, G., \& Celzard, A. (2010). Physicochemical characterization of sugar cane bagasse lignin oxidized by hydrogen peroxide. Polymer Degradation \& Stability, 95(4), 470-476. http://dx.doi.org/10.1016/j. polymdegradstab.2010.01.012.

28. Rosa, M. F., Chiou, B., Medeiros, E. S., Wood, D. F., Williams, T. G., Mattoso, L. H. C., Orts, W. J., \& Imam, S. H. (2009). Effect of fiber treatments on tensile and thermal properties of starch/ethylene vinyl alcohol copolymers/coir biocomposites. Bioresource Technology, 100(21), 5196-5202. PMid:19560341. http://dx.doi.org/10.1016/j.biortech.2009.03.085.

29. Galdeano, M. C., \& Grossmann, M. V. E. (2005). Effect of treatment with alkaline hydrogen peroxide associated with extrusion on color and hydration properties of oat hulls. Brazilian Archives of Biology and Technology, 48(1), 63-72. http://dx.doi.org/10.1590/S1516-89132005000100010.

30. Seibel, N. F., \& Beléia, A. P. (2009). The chemical characteristics and technological functionality of soybean based ingredients [Glycine Max (L.) Merrill]: carbohydrates and proteins. Brazilian Journal of Food Technology, 12(2), 113-122. http:// dx.doi.org/10.4260/BJFT20093607.

31. Bustos, F. M., Contreras, R. V., García, T. G., Nabeshima, E. H., \& Guzmán, I. V. (2011). Some functional characteristics of extruded blends of fiber from sugarcane bagasse, whey protein concentrate, and corn starch. Food Science and Technology, 31(4), 870-878. http://dx.doi.org/10.1590/S010120612011000400007.

32. Wang, X., Shen, X., \& Xu, W. (2012). Effect of hydrogen peroxide treatment on the properties of wool fabric. Applied Surface Science, 258(24), 10012-10016. http://dx.doi.org/10.1016/j. apsusc.2012.06.065

33. Gould, J. M., Jasberg, B. K., \& Cote, G. L. (1989). Structurefunction relationships of alkaline-peroxide treated lignocelluloses from wheat straw. Cereal Chemistry, 66(3), 213-217.

34. Fengel, D., \& Wegener, G. (1983). Wood-Chemistry, ultrastructure, reactions (pp. 133-181). Berlin: Walter de Gruyter.

35. Kabir, M. M., Wang, H., Lau, K. T., \& Cardona, F. (2012). Chemical treatments on plant-based natural fiber reinforced polymer composites: an overview. Composites. Part B, Engineering, 43(7), 2883-2892. http://dx.doi.org/10.1016/j. compositesb.2012.04.053. 
36. Lund, K., Sjostrom, K., \& Brelid, H. (2012). Alkali extraction of kraft pulp fibers: influence on fiber and fluff pulp properties. Journal of Engineered Fibers and Fabrics, 7(2), 30-39.

37. Teodoro, K. B. R., Teixeira, E. M., Corrêa, A. C., Campos, A., Marconcini, J. M., \& Mattoso, L. H. C. (2011). Whiskers from sisal fibers obtained under different acid hydrolysis conditions: effect of time and temperature of extraction. Polimeros: Ciência e Tecnologia, 21(4), 280-285. http://dx.doi. org/10.1590/S0104-14282011005000048.

38. Ardanuy, M., Antunes, M., \& Velasco, J. I. (2012). Vegetable fibres from agricultural residues as thermo-mechanical reinforcement in recycled polypropylene-based green foams. Waste Management (New York, N.Y.), 32(2), 256-263. PMid:22005571. http:// dx.doi.org/10.1016/j.wasman.2011.09.022.

39. Liu, L., Chen, H., \& Pan, D. (2012). Modification of polyacrylonitrile precursor fiber with hydrogen peroxide. FiberPolymers, 13(5), 587-592. http://dx.doi.org/10.1007/ s12221-012-0587-9.

40. Sun, R., Tomkinson, J., \& Ye, J. (2003). Physico-chemical and structural characterization of residual lignins isolated with TAED activated peroxide from ultrasound irradiated and alkali pre-treated wheat straw. Polymer Degradation \& Stability, 79(2), 241-251. http://dx.doi.org/10.1016/S01413910(02)00287-2.
41. Suradi, S. S., Yunus, R. M., Beg, M. D. H., \& Yusof, Z. A. M. (2009). Influence of pre-treatment on the properties of lignocellulose based biocomposite. In National Conference on Postgraduate Research (pp. 67-78). Pahang: University Malaysia.

42. Arbelaiz, A., Fernández, B., Valea, A., \& Mondragon, I. (2006). Mechanical properties of short flax fiber bundle/poly (3-caprolactone) composites: Influence of matrix modification and fiber content. Carbohydrate Polymers, 64(2), 224-232. http://dx.doi.org/10.1016/j.carbpol.2005.11.030.

43. Khan, G. M. A., \& Alam, M. S. (2012). Thermal characterization of chemically treated coconut husk fiber. Indian Journal of Fiber \& Textile Research, 37(1), 20-26. Retrieved in 11 August 2015, from http://nopr.niscair.res.in/handle/123456789/13681.

44. Chen, X., Yu, J., Zhang, Z., \& Lu, C. (2011). Study on structure and thermal stability properties of cellulose fibers from rice straw. Carbohydrate Polymers, 85(1), 245-250. http://dx.doi. org/10.1016/j.carbpol.2011.02.022.

Received: Aug. 11, 2015

Revised: Mar. 14, 2016

Accepted: Mar. 21, 2016 